\title{
Is There Growth in Grief: Measuring Posttraumatic Growth in the Grief Response
}

\author{
Joleen Schoulte, Zachary Sussman, Benjamin Tallman, Munni Deb, \\ Courtney Cornick, Elizabeth Altmaier \\ Department of Psychological and Quantitative Foundations, University of Iowa, Iowa City, USA \\ Email: Elizabeth-altmaier@uiowa.edu
}

Received April 3, 2012; revised May 10, 2012; accepted June 7, 2012

\begin{abstract}
Introduction: Grief is considered to be negative manifestations of affect, cognition, and behavior. However, persons who experience grief have also reported enduring positive outcomes in such domains as interpersonal relationships, personal strengths, and life perspectives. This review evaluated current measures of grief to determine if such positive outcomes can be adequately assessed. Methods: The Texas Revised Inventory of Grief, Grief Experience Inventory, Bereavement Phenomenology Questionnaire, Core Bereavement Items, Continuing Bonds Scale, and Hogan Grief Reaction Checklist (currently the most common measures of grief) are reviewed. Results: Only one of the reviewed measures assessed posttraumatic growth as a component of grief (i.e., Hogan Grief Reaction Checklist). Conclusion: Since posttraumatic growth and negative psychological adjustment after traumatic events can coexist, it is important that measures of grief used in both clinical and research domains allow an assessment of positive response.
\end{abstract}

Keywords: Posttraumatic Growth; Grief; Bereavement; Adjustment; Assessment

\section{Introduction}

In Western culture and in the English language, grief refers to an emotion of sorrow and sadness [1]. Grief can also be explained as a set of reactions [2]: affect (depression, anger, anhedonia), cognitions (preoccupation with the deceased, a sense of unreality, problems with memory or concentration), and physiological states (loss of appetite, sleep disturbance, somatic complaints). Studies [3] that examine grieving date back to the early 17th century when Burton [4] observed a symptom cluster that he termed melancholy. According to Freud [5], bereaved persons must pursue "grief work" to address the loss of a loved one, to reduce their distress, and to resume normal living.

Most bereaved individuals experience ongoing distress, such as thoughts of the lost loved one and depressed moods, but symptoms decline gradually. Even in the first year after loss, there is an acceptance of the loss, re-engagement in productive work and a return to leisure activities [6]. However, some bereaved persons experience a delayed or even indefinite period of disturbance. Such prolonged grief differs from normative grief in that the person who experiences it displays significant functional impairment in work, social relationships, and other areas of life [7].

Conceptualization of grief is predicated on the as- sumption that bereavement leads only to negative states within the grief response. However, based in positive psychology, posttraumatic growth is a concept that reflects the potential for negative events, from normative occurrences through traumatic events, to lead to enduring personal growth [8]. Evidence [cf. 9-14] suggests that individuals experience and demonstrate personal growth following bereavement and after traumas such as sexual assault, diagnosis and treatment of cancer, natural disasters (e.g., tornadoes, tsunamis), and national calamities (e.g., September 11, 2001 in the US). Although a variety of terms-benefit finding [15], stress-related growth [16], and adversarial growth [9]—have been used to describe these positive changes, the term posttraumatic growth is used in this review to denote a positive, enduring psychological change that results from a challenging or traumatic life event $[9,16]$.

One life area in which persons can demonstrate posttraumatic growth is bereavement. Although distress follows bereavement, bereaved individuals have also reported themes of growth, meaning construction, and sense making $[17,18]$. Posttraumatic growth includes the emergence of new possibilities in life, such as a change in career; improvements in interpersonal relationships, such as increased empathy for others; changes in perception of personal strengths and life philosophy; and spiritual or existential changes [cf. 19]. 
Davis et al. [20] suggested that finding benefit and making sense of loss play important roles in adjustment following bereavement. For example, Znoj and Keller [21] demonstrated that reports of personal growth among parents who had lost a child were associated with improved adjustment. More recently, Keese et al. [18] investigated meaning making and benefit finding among 157 parents who had experienced the loss of a child, and reported that both of these activities predicted adjustment.

According to Tedeschi and Calhoun, "posttraumatic growth might be considered the highest form of change associated with grief” [19, p. 31]. Although individuals have reported growth following bereavement, the degree to which such growth is likely to be identified in current grief assessment is unknown. Many measures of grief are used in both research and clinical domains. However, unless positive growth is assessed within grief, it is difficult to know the degree to which growth occurs. The purpose of this review is to evaluate current measures of grief-including the provision of updated psychometric and validity information-and to consider whether measures assess growth or components of growth, such as meaning making or benefit finding.

\section{Review of Measures}

\subsection{Texas Revised Inventory of Grief}

The oldest and most widely used measure of grief is the Texas Revised Inventory of Grief (TRIG). Items for the TRIG were originally based on review of research literature and clinical expertise of the authors. The TRIG [22] has two subscales: Current Grief (13 items) and Past Disruption (eight items). Items contain sentences of personal description to which the participant responds on a five-point scale $(1=$ completely false to $5=$ completely true). Examples of items include "I still cry when I think of the person who died" and "I found it hard to sleep after the person died".

Neimeyer and Hogan [23] summarized the TRIG's psychometric qualities. Internal consistency for the two subscales ranges from 0.77 to 0.87 (Current Grief) and 0.86 to 0.89 (Past Disruption). In the original manual, Faschingbauer [24] reported the use of exploratory factor analysis to achieve construct validity and select items with factor loadings greater than 0.40 . Convergent validity is supported by a coefficient of 0.87 with the Inventory of Traumatic Grief [25].

The TRIG has been criticized [26] for item redundancy and for conceptual overlap with other domains such as depression. Additionally, although the TRIG was meant to assess stages of response, there are no validity data supporting assessment of stage of grieving.

\subsection{Grief Experience Inventory}

To assess the process of bereavement, Sanders et al. [27] developed the Grief Experience Inventory (GEI). Statements made by grieving individuals were examined and compiled, and a Q-sort technique was used by the scale developers to construct 135 true-false items. The GEI is comprised of nine bereavement scales and three validity scales. Bereavement scales measure Despair, Anger/ Hostility, Guilt, Social Isolation, Loss of Control, Rumination, Depersonalization, and Death and Anxiety. Validity scales assess for impression management and random responding: Denial, Atypical Response, and Social Desirability. Items describe present states such as "I find I am often irritated by others," and "it is difficult to part with the clothing or personal items of the deceased."

Validity of the GEI is suggested [27] by differences between bereaved and non-bereaved individuals; individuals with higher scores also report greater difficulty with accepting the loss of a loved one. Factor analysis revealed that three dominant factors do not correspond to the scale's structure; the largest factor appears to measure depression.

\subsection{Bereavement Phenomenology Questionnaire}

The Bereavement Phenomenology Questionnaire (BPQ) is a 22-item measure to assess emotional experiences of grief (e.g., anger or guilt); images and thoughts of the deceased; and the degree and form of attachment behaviors [28]. The original item pool was derived from statements that reflect the views of clinicians, researchers, and theorists working in the field of bereavement. Additional items were derived through analyses of brief, semi-structured interviews with recent widowers.

Respondents endorse items on a four-point scale $(0=$ never to 3 = often) with regard to the frequency with which bereavement-related phenomena had been experienced. Examples of items include "have you felt as though you have seen her, heard her, or felt as though she has touched you" or "have you had feelings of nostalgia when thinking about her.” Responses are summed to produce a total score, where higher scores indicate greater frequency of bereavement-related phenomena.

Psychometric properties for the BPQ have been reported [28]. Internal consistency was demonstrated by a Cronbach's alpha of 0.83 and internal reliability by a mean item-total correlation of 0.41 . A study examining bereavement reactions among 243 bereaved spouses and adult children failed to support the original four factors of the BPQ whereas evidence for a single factor was supported [29].

\subsection{Core Bereavement Items}

The Core Bereavement Items (CBI) is a 17-item measure 
designed to assess the intensity of bereavement reactions [30]. Individuals respond to items on a four-point scale ( $1=$ never to $4=a$ lot of the time, continuously, or always). Scores are summed across all subscales, and higher scores indicate greater frequency and intensity of experiencing bereavement-related phenomena. Examples of items include "do thoughts of ' $x$ ' come into your mind whether you wish it or not", "do you feel distress/pain if for any reason you are confronted with the reality that ' $x$ ' is not present/not coming back," and "do reminders of ' $\mathrm{x}$ ' such as photos, situations, music, places, etc. cause you to feel loss of enjoyment”.

The CBI is comprised of three subscales: Images and Thoughts, Acute Separation, and Grief. Subscales for the CBI were derived from a factor analysis of the original form of the BPQ; factor loadings ranged from 0.73 to 0.77 . Three of the original factors were selected based on face validity in representing bereavement, ability to discriminate between groups, and sensitivity to change over time.

\subsection{Continuing Bonds Scale}

The Continuing Bonds Scale (CBS) is an 11-item measure to assess "different ways in which the [bereaved] maintain an ongoing psychological connection with the deceased at a later point after the death” [31, p. 112]. Items were constructed based on research that concerns the survivor's intent to maintain a bond with the deceased through memories, possessions, identifying with the deceased, maintaining the legacy of the deceased, use of the deceased as a standard, and reminiscing with others about the deceased.

On a five-point scale $(1=$ not at all true to $5=$ very true), individuals respond whether an item is true with regards to their current relationship with the deceased. A total score is derived from summing responses: Higher scores indicate the greater number of ways of maintaining a bond with the deceased as well as increased frequency of these methods. Examples of items include "even though no longer physically present, my spouse continues to be a loving presence in my life" and "I have many fond memories that bring joy to me".

The CBS was normed on a sample of 39 conjugally bereaved adults (13 men and 26 women; ages 21 - 55) who were married to or lived with a deceased partner for a minimum of three years. Internal consistency evidence is provided by a Cronbach's alpha of 0.87 . Concurrent validity reported with significant correlation between the CBS and the TRIG five years post-loss. Discriminant validity evidence is lacking.

\subsection{Hogan Grief Reaction Checklist}

The Hogan Grief Reaction Checklist (HGRC) was de- veloped to measure the trajectory and nature of the bereavement process. Using interview and anecdotal data, Hogan et al. [32] constructed six grief categories and items were reviewed by several focus groups and a panel of experts. The final version of the HGRC is comprised of 61 items selected based on factor analysis. Participants are requested to answer items that are based on how they have been feeling during the past two weeks on a fivepoint scale $(1=$ does not describe $m e$ at all to $5=d e$ scribes me very well).

The HGRC subscales are as follows: Despair (13 items) assesses hopelessness and loneliness (e.g., "my hopes are shattered"); Panic Behavior (14 items), fear and somatic symptoms (e.g., "I worry excessively"); Blame and Anger (seven items), irritation and feelings of injustice (e.g., "I am resentful"); Disorganization (eight items), difficulty with concentrating and problems with retaining and recalling information (e.g., "tasks seem insurmountable"); Detachment (eight items), disconnectedness from oneself and others (e.g., "I feel unable to cope"); and Personal Growth (12 items), becoming more compassionate, caring, and forgiving as a result of the bereavement process (e.g., "I feel as though I am a better person").

The psychometric properties of the HGRC were evaluated using four sample groups. The original 100 items were administered to 586 adults who experienced the death of a family member. Test-retest reliability was assessed over a four-week interval in a sample of 47 undergraduate nursing students who experienced the loss of a loved one. Internal consistency (Cronbach's alpha) was 0.90 for the total scale and ranged from 0.82 to 0.90 for the subscales.

Relationships of the HGRC subscales with the TRIG and the GEI were examined to establish the convergent and divergent validity of the subscales. The HGRC demonstrated concurrent validity with the GEI. A later study provided additional support for concurrent validity of the HRGC Personal Growth subscale being inversely correlated with all GEI subscales [33]. Confirmatory factor analysis supported the construct validity of the revised 61 items in a sample of 209 parents.

The authors of the HRGC posit that personal growth is an integral aspect of the grief process, a finding that was supported empirically in the initial scale development. Additionally, focus group members who experienced a death of a significant other endorsed personal growth items during the development of the HRGC.

\section{Results}

Posttraumatic growth, finding benefit, and meaning making are processes that take place following stressful life events, including bereavement. It is noteworthy that an extensive review [34] placed bereavement in the contexts 
of stress theory, attachment theory, emotion theories, and trauma. In each of these contexts, there is a theoretically well-established possibility for positive emotions and actions that do not constitute denial or other nonadaptive responses. However, in order to understand the role that positive emotions and actions play in the grief response, there must be accurate assessment of these positive, adaptive processes.

Of the measures that were reviewed, only the HGRC assessed posttraumatic growth within grief. The Personal Growth subscale of the HGRC measures "spiritual and existential awareness, including a sense of becoming more forgiving, caring, compassionate, hopeful, and tolerant of self and others" [33, p. 17]. Items in the Personal Growth scale of the HRGC parallel growth domains that are frequently cited in the literature: changes in personal strength (e.g., "I am stronger because of the grief I have experienced"); alterations in life perspectives (e.g., "I have a better outlook on life"); and new life directions (e.g., "I have hope for the future").

\section{Discussion}

Earlier conceptualization of grief as a singularly negative experience likely occurred for several reasons. In a study of caregivers who experienced the loss of their partners to AIDS, researchers stated that their finding that caregivers demonstrated the search for and articulation of positive meaning in the partner's loss was "startling and initially counterintuitive" [35, p. 126]. An assumption that a negative state cannot coexist with positive feelings would lead researchers and clinicians away from inquiring about positive indicators in the presence of a negative event. Furthermore, expressions of positive thoughts and feelings in the context of negative events may have been taken as evidence that the person is denying the event or its impact on him or her [36]. In this context, expression of meaning, benefit, and growth may have been considered an illusionary response in the face of the need to process the distress and depression.

Empirical research supports posttraumatic growth and negative psychological adjustment (e.g., posttraumatic stress disorder or PTSD) co-occurring following bereavement $[37,38]$. In a study of 97 Holocaust survivors, Lev-Wiesel and Amir [38] found that arousal symptoms associated with PTSD coexisted with reports of posttraumatic growth. Qualitative research also supports multidimensional response following bereavement. For example, Cadell [39] examined positive and negative changes among fifteen caregivers who lost a loved one to complications related to HIV/AIDS. Results revealed themes of psychological distress, personal growth, humor, social support, spirituality, and existential issues following bereavement. The co-occurrence of positive and negative processes following bereavement lends support for posttraumatic growth as a facet of a multidimensional response to bereavement. The burgeoning positive psychology movement [40] has made significant progress in research focused on strength-based psychology. Within the context of grief, however, there is still a gap between the theoretical construct of grief and psychometrically sound measures to assess a multidimensional grief response.

\section{Conclusions}

The term expert companion refers to the role that clinicians take to guide individuals through highly stressful events [41]. Expert companions help individuals to manage emotional distress, facilitate a new understanding about beliefs and goals, and assist in revising a life narrative. For the clinician, the "most important task is to guide patients in moving from merely suffering, to suffering meaningfully" [41, p. 216]. It is important to keep in mind that not all individuals experience growth as part of their grief response. Therefore, encouraging all bereaved or grieving persons toward articulating growth when growth is not present may increase suffering.

However, in order to identify, and promote, positive changes following bereavement that co-occur during grief, accurate assessment is necessary. We encourage use of the HGRC, and further investigation by clinicians and researchers regarding posttraumatic growth after bereavement.

\section{Acknowledgements}

The authors note with appreciation the assistance of the Iowa Testing Program.

\section{REFERENCES}

[1] P. C. Rosenblatt, "Grief across Cultures: A Review and Research Agenda,” In: M. S. Stroebe, R. O. Hansson, H. Schut and W. Stroebe, Eds., Handbook of Bereavement Research and Practice: Advances in Theory and Intervention, American Psychological Association, Washington DC, 2008, pp. 207-222.

[2] R. S. Weiss, “The Nature and Causes of Grief,” In: M. S. Stroebe, R. O. Hansson, H. Schut and W. Stroebe, Eds., Handbook of Bereavement Research and Practice: Advances in Theory and Intervention, American Psychological Association, Washington DC, 2008, pp. 29-44. doi:10.1037/10436-001

[3] C. M. Parkes, "A Historical Overview of the Scientific Study of Bereavement,” In: M. S. Stroebe, R. O. Hansson, W. Stroebe and H. Schut, Eds., Handbook of Bereavement Research: Consequences, Coping, and Care, American Psychological Association, Washington DC, 2001, pp. 25-45.

[4] R. Burton, "The Anatomy of Melancholy, What It Is," Theatrum Orbis Terrarum, Amsterdam, 1621. 
[5] S. Freud, "Mourning and Melancholia,” In: J. Strachey, Ed., The Standard Edition of the Complete Psychological Works of Sigmund Freud (Vol. 14), Hogarth Press, London, 1953.

[6] H. G. Prigerson, "Complicated Grief: When the Path of Adjustment Leads to a Dead-End,” Bereavement Care, Vol. 23, No. 3, 2004, pp. 38-40. doi:10.1080/02682620408657612

[7] H. G. Prigerson and S. C. Jacobs, "Traumatic Grief as a Distinct Disorder: A Rationale, Consensus Criteria, and a Preliminary Empirical Test,” In: M. S. Stroebe, R. O. Hansson, W. Stroebe and H. Schut, Eds., Handbook of Bereavement Research: Consequences, Coping, and Care, American Psychological Association, Washington DC, 2001, pp. 613-646. doi:10.1037/10436-026

[8] S. Joseph and P. A. Linley, "Positive Psychological Perspectives on Posttraumatic Stress: An Integrative Psychosocial Framework,” In: S. Joseph and P. A. Linley, Eds., Trauma, Recovery, and Growth, Wiley, New York, 2008, pp. 3-20.

http://media.wiley.com/product_data/excerpt/23/0470075 0/0470075023.pdf

[9] P. A. Linley and S. Joseph, “Applied Positive Psychology: A New Perspective for Professional Practice,” In: P. A. Linley and S. Joseph, Eds., Positive Psychology in Practice, Wiley, New York, 2004, pp. 3-12.

[10] R. G. Tedeschi and L. G. Calhoun, "Posttraumatic Growth: Conceptual Foundations and Empirical Evidence [Target Article]," Psychological Inquiry, Vol. 15, No. 1, 2004, pp. 1-18. doi:10.1207/s15327965pli1501_01 http://www.jstor.org/stable/20447194

[11] P. Frazier, A. Conlon and T. Glaser, "Positive and Negative Life Changes Following Sexual Assault,” Journal of Consulting and Clinical Psychology, Vol. 69, No. 6, 2001, pp. 1048-1055. doi:10.1037/0022-006X.69.6.1048

[12] B. A. Tallman, E. M. Altmaier and C. Garcia, "Finding Benefit from Cancer," Journal of Counseling Psychology, Vol. 54, No. 4, 2007, pp. 481-487. doi:10.1037/0022-0167.54.4.481

[13] N. A. Karanci and C. Acarturk, "Post-traumatic Growth among Marmara Earthquake Survivors Involved in Disaster Preparedness as Volunteers,” Traumatology, Vol. 11, No. 4, 2005, pp. 307-323. doi:10.1177/153476560501100409

[14] A. L. Ai, T. Cascio, L. K. Santangelo, and T. EvansCampbell, "Hope, Meaning, and Growth Following the September 11, 2001, Terrorist Attacks," Journal of Interpersonal Violence, Vol. 20, No. 5, 2005, pp. 523-548. doi:10.1177/0886260504272896

[15] M. H. Antoni, J. M. Lehman, K. M. Kilbourn, A. E. Boyers, J. L. Culver, S. M. Alferi, et al., "Cognitive-Behavioral Stress Management Intervention Decreases the Prevalence of Depression and Enhances Benefit Finding among Women under the Treatment for Early-Stage Breast Cancer,” Health Psychology, Vol. 20, No. 1, 2001, pp. 20-32. doi:10.1037/0278-6133.20.1.20

[16] C. L. Park, L. H. Cohen, and R. L. Murch, "Assessment and Prediction of Stress-Related Growth," Journal of Personality, Vol. 64, No. 1, 1996, pp. 71-105.

\section{doi:10.1111/j.1467-6494.1996.tb00815.x}

[17] S. Cadell and R. Sullivan, "Posttraumatic Growth and HIV Bereavement: Where Does It Start and When Does It End?” Traumatology, Vol. 12, No. 1, 2006, pp. 45-59. doi:10.1177/153476560601200104

[18] N. J. Keesee, J. M. Currier and R. A. Neimeyer, "Predictors of Grief Following the Death of One's Child: The Contribution of Finding Meaning," Journal of Clinical Psychology, Vol. 64, No. 10, 2008, pp. 1145-1163. doi:10.1002/jclp.20502

[19] R. G. Tedeschi and L. G. Calhoun, "Beyond the Concept of Recovery: Growth and the Experience of Loss [Comment on Balk, 2004, Vol. 28, No. 4],” Death Studies, Vol. 32, No. 1, 2008, pp. 27-39. doi:10.1080/07481180701741251

[20] C. G. Davis, S. Nolen-Hoeksema and J. Larson, "Making Sense of Loss and Benefiting from the Experience: Two Construals of Meaning," Journal of Personality and Social Psychology, Vol. 72, No. 2, 1998, pp. 561-574. doi:10.1037/0022-3514.75.2.561

[21] H. J. Znoj and D. Keller, "Mourning Parents: Considering Safeguards and Their Relation to Health," Death Studies, Vol. 26, No. 7, 2002, pp. 545-565. doi:10.1080/074811802760191708

[22] T. R. Faschingbauer, S. Zisook, and R. A. Devaul, "The Texas Revised Inventory of Grief,” In: S. Zisook, Ed., Biopsychosocial Aspects of Bereavement, American Psychiatric Press, Washington DC, 1987, pp. 111-124.

[23] R. A. Neimeyer and N. S. Hogan, "Quantitative or Qualitative? Measurement Issues in the Study of Grief,” In: M. S. Stroebe, R. O. Hansson, W. Stroebe and H. Schut, Eds., Handbook of Bereavement Research: Consequences, Coping, and Care, American Psychological Association, Washington DC, 2001, pp. 89-118. doi:10.1037/10436-004

[24] T. R. Faschingbauer, "Texas Revised Inventory of Grief,” Honeycomb Publishing, Houston, 1981.

[25] H. G. Prigerson, P. K. Maciejewski, C. F. Reynolds III, A. J. Bierhals, J. T. Newsom, A. Fasiczka, et al., "Inventory of Complicated Grief: A Scale to Measure Maladaptive Symptoms of Loss," Psychiatry Research, Vol. 59, No. 1-2, 1995, pp. 65-79. doi:10.1016/0165-1781(95)02757-2

[26] R. O. Hansson, B. N. Carpenter and S. K. Fairchild, "Measurement Issues in Bereavement," In: M. S. Stroebe, W. Stroebe and R. O. Hansson, Eds., Handbook of Bereavement, Cambridge University Press, Cambridge, 1993, pp. 62-74. doi:10.1017/CBO9780511664076.005

[27] C. M. Sanders, P. A. Mauger and P. N. Strong, “A Manual for the Grief Experience Inventory,” The Center for the Study of Separation and Loss, Blowing Rock, 1985.

[28] G. J. A. Byrne and B. Raphael, “A Longitudinal Study of Bereavement Phenomena in Recently Widowed Elderly Men,” Psychological Medicine, Vol. 24, No. 2, 1994, pp. 411-421. doi:10.1017/S0033291700027380

[29] D. W. Kissane, S. Bloch and D. P. McKenzie, "The Bereavement Phenomenology Questionnaire: A Single Factor Only," Australian and New Zealand Journal of Psychiatry, Vol. 31, No. 3, 1997, pp. 370-374. 


\section{doi:10.3109/00048679709073846}

[30] P. Burnett, W. Middleton, B. Raphael and N. Martinek, “Measuring Core Bereavement Phenomena," Psychological Medicine, Vol. 27, No. 1, 1997, pp. 49-57. doi:10.1017/S0033291796004151

http://journals.cambridge.org/action/displayAbstract?from Page $=$ online $\&$ aid $=25253$

[31] N. P. Field, E. Gal-Oz and G. A. Bonanno, "Continuing Bonds and Adjustment at 5 Years after the Death of a Spouse,” Journal of Consulting and Clinical Psychology, Vol. 71, No. 1, 2003, pp. 110-117. doi:10.1037/0022-006X.71.1.110

[32] N. S. Hogan, D. B. Greenfield and L. A. Schmidt, "Development and Validation of the Hogan Grief Reaction Checklist,” Death Studies, Vol. 25, No. 1, 2001, pp. 1-32. doi:10.1080/074811801750058609

[33] L. A. Gamino, K. W. Sewell and L. W. Easterling, "Scott and White Grief Study_Phase 2: Toward an Adaptive Model of Grief,” Death Studies, Vol. 24, No. 7, 2000, pp. 633-660. doi:10.1080/07481180050132820

[34] G. A. Bonanno and S. Kaltman, "Toward an Integrative Perspective on Bereavement," Psychological Bulletin, Vol. 125, No. 6, 1999, pp. 760-776. doi:10.1037/0033-2909.125.6.760

[35] S. Folkman, "Positive Psychological States and Coping with Severe Stress," Social Science and Medicine, Vol. 45, No. 8, 1997, pp. 1207-1221. doi:10.1016/S0277-9536(97)00040-3

[36] L. G. Aspinwall and R. G. Tedeschi, "The Value of Positive Psychology for Health Psychology: Progress and Pit- falls in Examining the Relation of Positive Phenomena to Health [Original Article]," Annals of Behavioral Medicine, Vol. 39, No. 1, 2010, pp. 4-15. doi:10.1007/s12160-009-9153-0

[37] S. Cadell, C. Regehr and D. Hemsworth, "Factors Contributing to Posttraumatic Growth: A Proposed Structural Equation Model," American Journal of Orthopsychiatry, Vol. 73, No. 3, 2003, pp. 279-287. doi:10.1037/0002-9432.73.3.279

[38] R. Lev-Wiesel and M. Amir, "Posttraumatic Growth among Holocaust Child Survivors," Journal of Loss and Trauma, Vol. 8, No. 4, 2003, pp. 229-237. doi:10.1080/15325020305884

[39] S. Cadell, "The Sun Always Comes Out after It Rains: Understanding Posttraumatic Growth in HIV Caregivers," Health and Social Work, Vol. 32, No. 3, 2007, pp. 169176. doi:10.1093/hsw/32.3.169

[40] M. E. P. Seligman and M. Csikszentmihalyi, "Positive Psychology: An Introduction,” American Psychologist, Vol. 55, No. 1, 2000, pp. 5-14. doi:10.1037/0003-066X.55.1.5

[41] R. G. Tedeschi and L. G. Calhoun, "The Clinician as Expert Companion,” In: C. L. Park, S. C. Lechner, M. H. Antoni and A. L. Stanton, Eds., Medical Illness and Positive Life Change: Can Crisis Lead to Personal Transformation? American Psychological Association, Washington DC, 2009, pp. 215-235. doi:10.1037/11854-012 